\title{
Perbandingan Keberhasilan dan Waktu Intubasi Endotrakeal pada Manekin antara Bantal Intubasi Standar dan Bantal Intubasi Modifikasi
}

\author{
Sendy Setiawan Permana, ${ }^{1}$ Erwin Pradian, ${ }^{2}$ Dedi Fitri Yadi ${ }^{2}$ \\ ${ }^{1}$ Bagian Anestesi RSUD Dabo lingga, Riau, ${ }^{2}$ Departemen Anestesiologi dan Terapi Intensif \\ Fakultas Kedokteran Universitas Padjadjaran/RSUP Dr. Hasan Sadikin Bandung
}

\begin{abstract}
Abstrak
Intubasi pipa endotrakeal adalah standar baku manajemen jalan napas. Direct laryngoscopy dengan memposisikan kepala dan leher secara sniffing position menggunakan bantal agar visualisasi glotis optimal merupakan kunci untuk melakukan tindakan intubasi endotrakea. Tujuan penelitian adalah membandingkan keberhasilan dan lama waktu intubasi endotrakea pada manekin menggunakan bantal intubasi standar dengan bantal intubasi modifikasi. Penelitian menggunakan metode crossover randomized study dengan teknik nonprobability sampling oleh 31 orang residen anestesi pada manekin di ruang skill lab Departemen Anestesiologi dan Terapi Intesif FK Unpad RSUP Dr. Hasan Sadikin Bandung periode Februari 2018. Penelitian dibagi menjadi kelompok bantal intubasi standar (A) melakukan intubasi endotrakeal menggunakan bantal intubasi standar dilanjutkan menggunakan bantal intubasi modifikasi. Kelompok bantal modifikasi (B) melakukan intubasi endotrakeal dengan bantal intubasi modifikasi dilanjutkan menggunakan bantal intubasi standar, dinilai keberhasilan dan lama waktu intubasi. Data dianalisis dengan uji-t dan Uji Mann-Whitney dengan $p<0,05$ dianggap bermakna. Analisis data statistik menunjukkan angka keberhasilan yang sama pada kedua kelompok, sedangkan lama waktu intubasi endotrakea lebih singkat pada kelompok bantal modifikasi dibanding dengan kelompok bantal standar yang berbeda bermakna $(\mathrm{p}<0,05)$. Simpulan penelitian menunjukkan waktu intubasi menggunakan bantal intubasi modifikasi lebih singkat dibanding dengan menggunakan bantal standar, sedangkan keberhasilan intubasi sama pada kedua kelompok.
\end{abstract}

Kata kunci: Bantal intubasi, intubasi endotrakea, sniffing position

\section{Comparison of Successful Intubation and Time of Intubation in Mannequin using Standard Intubation Pillow and Modified Intubation Pillow}

\begin{abstract}
Abstrak
Endothracheal intubation is the gold standard in airway management. Direct laryngoscopy by positioning the head and the neck in a sniffing position with the help of a pillow will facilitate optimal visualization of the trachea, which is the key to a successful endotracheal intubation. The purpose of this study was to assess the time needed to intubate mannequin using modified intubation pillow when compared to standard intubation pillow. This was a crossover randomized study using nonprobability sampling technique conducted inn March 2018 on of 31 anesthesia residents who were working on a mannequin in the Skill Laboratory of Anesthesiology and Intensive Therapy Department of Dr. Hasan Sadikin General Central Hospital. Subjects were divided into two groups: group A that used the standard intubation pillow, followed by the modified intubation pillow and group B that used the modified intubation pillow, followed by the standard intubation pillow. The success rate and the time needed to intubate were recorded. Data were analyzed using t-test and Mann-Whitney test with a p score of $<0.05$ considered to be significant. The statistical analysis showed the same success rate in both groups, while the time needed to intubate was shorter in the modified pillow group with $\mathrm{p}<0.05$. Hence, the use of modified intubation pillow shorten the time needed to intubate, while the success rate is similar when compared to standard pillow.
\end{abstract}

Key words: Endotracheal intubation, intubation pillow, sniffing position

Korespondensi: Sendy Setiawan Permana, dr., SpAn, Bagian Anestesi RSUD Dabo lingga, Jl. Kesehatan No. 1 Dabo Singkep, Kabupaten Lingga, Kepulauan Riau, Tlpn. 0776-322605, Email sendy_sp@yahoo.com 


\section{Pendahuluan}

Tindakan intubasi pipa endotrakea merupakan penanganan jalan napas definitf yang memberikan proteksi maksimal terhadap kejadian aspirasi isi atau cairan lambung. Intubasi pipa endotrakea dilakukan dengan menempatkan pipa endotrakea ke dalam trakea sebagai alat saluran untuk ventilasi atau terapi jika ada masalah paru. Intubasi endotrakea merupakan teknik nonoperatif yang cepat, sederhana, dan aman untuk memfasilitasi seluruh tujuan manajemen jalan napas antara lain menjaga jalan napas agar selalu terbuka, melindungi paru dari aspirasi, serta memfasilitasi ventilasi dengan kebocoran minimal selama terapi ventilasi mekanik. Teknik ini merupakan gold standard untuk manajemen jalan napas. ${ }^{1}$

Penggunaan bantal dapat memberikan tampilan direct laryngoscopy yang lebih baik dengan memperbesar sudut atlantoaxialoccipital dan memperbesar ruang submandibular. Selain itu, ketinggian bantal yang berbeda akan menghasilkan visualisasi glotis yang berbeda sehingga banyak penelitian dilakukan untuk mengukur ketinggian bantal yang optimal untuk intubasi. ${ }^{5-6}$ Bantal intubasi standar yang ada rerata memiliki tinggi 5-7 $\mathrm{cm}$. Pada beberapa penelitian dibuat bantal intubasi modifikasi yang dapat dipompa bertujuan menghasilkan visualisai glotis yang lebih baik dan dapat disesuaikan dengan kondisi individual tiap pasien. Semua tindakan di atas bertujuan menghasilkan visualisasi glotis yang optimal. Salah satu penilaian tampilan visualisasi glotis, yaitu percentage of glotic opening (POGO) yang ditentukan dengan persentase pita suara dari komisura anterior hingga takik aritenoid yang dapat dilihat saat tindakan direct laryngoscopy. Penilaian ini terbukti mempunyai reliabilitas antarpeneliti lebih tinggi dibanding dengan klasifikasi Cormack-Lehane dan lebih bermanfaat untuk penelitian lariongoskopi langsung maupun tidak langsung.

Penelitian menyatakan penggunaan bantal intubasi yang dapat dipompa dan diatur ketinggiannya menghasilkan posisi untuk intubasi yang lebih baik karena tercapainya aksis yang lurus dari mulut, faring, dan laring sehingga lebih mudah dalam melakukan tindakan intubasi dan tingkat keberhasilan lebih tinggi dibanding dengan bantal intubasi standar. ${ }^{7-10}$

Penelitian yang dilakukan kepada konsultan anestesi dan residen menyatakan waktu intubasi menggunakan bantal intubasi modifikasi yang dipompa lebih cepat dibanding dengan bantal intubasi standar dan tingkat keberhasilannya lebih baik menggunakan bantal intubasi modifikasi. ${ }^{11}$

Para peneliti dalam bidang anestesi memfokuskan pengembangan manjemen jalan napas menggunakan simulator khususnya manekin untuk jalan napas. ${ }^{12-14}$ Penggunaan manekin bukan hanya untuk latihan manajemen jalan napas dan juga untuk penelitian mengenai manejemen jalan napas. ${ }^{15-16}$

Kemampuan untuk menghasilkan keadaan baik jalan napas yang normal maupun sulit telah menghasilkan pemahaman yang lebih baik tentang manipulasi jalan napas yang berbeda dan membantu untuk penilaian terhadap alat-alat baru untuk manajemen jalan napas. ${ }^{17-18}$

Tujuan lain dibuatnya simulator seperti manekin ini adalah aspek keselamatan pasien yang sesuai dengan prinsip bioetika, yaitu "first do no harm". Model simulator merupakan cara inovatif dalam proses pembelajaran, dan dapat dilakukan tindakan medis tanpa risiko. Aspek etik lain yang menjadi pertimbangan adalah pasien autonomi bahwa pasien berhak menentukan pilihan terhadap tindakan medis yang akan dilakukan kepada mereka. ${ }^{19}$

Penelitian ini sudah pernah dilakukan di tempat lain, namun pada penelitian lain menggunakan pompa tangan, sedangkan bantal intubasi modifikasi pada penelitian ini menggunakan pompa kaki dengan pertimbangan agar tidak memerlukan bantuan orang lain saat penggunaannya dan kedua tangan subjek penelitian dapat mudah melakukan tindakan intubasi tanpa terganggu sambil menggunakan pompa tangan. Modifikasi ini diharapkan dapat membantu 
tenaga medis untuk mempermudah melakukan intubasi endotrakea. Alat ini adalah alat baru yang belum diketahui tentang keamanannya maka penelitian ini dilakukan terlebih dahulu kepada manekin.

\section{Subjek dan Metode}

Penelitian ini adalah penelitian eksperimental prospektif dengan rancangan cross-sectional. Subjek penelitian adalah mahasiswa program pendidikan dokter spesialis (PPDS) Departemen Anestesi dan Terapi Intensif Fakultas Kedokteran Universitas Padjadjaran. Penelitian dilakukan di ruang skill lab Departemen Anestesiologi dan Terapi Intensif Rumah Sakit Dr. Hasan Sadikin Bandung mulai dari tanggal 20 sampai 28 Februari 2018. Kriteriainklusi penelitianiniadalah mahasiswa PPDS bagian Anestesiologi dan Terapi Intensif Fakultas Kedokteran Universitas Padjadjaran level kompetensi 3.

Penentuan besar sampel digunakan rumus untuk menguji rerata dua kelompok dengan pemilihan tingkat kepercayaan $(1-\alpha)$ sebesar $95 \%$ dan besarnya uji sebesar $90 \%$ dengan besar sampel minimal yang dibutuhkan adalah 31 mahasiswa. Sampel dibagi menjadi 2 kelompok, kelompok A melakukan intubasi endotrakea menggunakan bantal intubasi modifikasi, dilanjutkan menggunakan bantal intubasi standar. Kelompok B melakukan intubasi endotrakea menggunakan bantal intubasi standar dilanjutkan menggunakan bantal intubasi modifikasi, randomisasi dengan metode permutasi blok.

Peneliti menunjukkan cara melakukan intubasi endotrakea pada menekin dengan menggunakan bantal intubasi standar dan bantal intubasi modifikasi yang dapat diatur ketinggiannya. Pada kelompok A subjek penelitian mengatur tinggi meja intubasi yang sudah terdapat manekin sejajar dengan prosesus sifoideus subjek penelitian yang akan melakukan tindakan. Bantal intubasi terdiri atas 2 bagian, bagian bantal diletakkan di bawah kepala manekin yang berfungsi sebagai bantal intubasi dan bagian pompa diletakkan di lantai. Setelah itu dilakukan tindakan laryngoscopy menggunakan CMAC videolaryngoscope. Bagian pompa bantal diinjak sehingga udara mengalir dan mengisi balon dan membuat bagian bantal yang berada di bagian kepala manekin mengembang.

Balon dipompa sampai visualisasi glotis yang paling optimal menurut subjek penelitian dan dinilai skor POGO dengan nilai 0-100\% (100\% jika visualiasi pita suara dari komisura anterior hingga takik aritenoid terlihat semua, $0 \%$ bilaglotis tidak terlihatsama sekali) melalui CMAC. Peneliti mencatat nilai keberhasilan dan lama waktu intubasi. Subjek penelitian melakukan kembali tindakan intubasi dengan bantal intubasi standar, dimulai dari tindakan laryngoscopy menggunakan CMAC videolaryngoscope dan dinilai skor POGO melalui CMAC. Peneliti mencatat nilai keberhasilan dan lama waktu intubasi untuk tindakan intubasi menggunakan bantal standar.

Untuk kelompok B, subjek penelitian melakukan tindakan intubasi dengan bantal standar terlebih dahulu, setelah itu intubasi dengan bantal intubasi modifikasi, peneliti mencatat nilai keberhasilan, lama waktu intubasi, dan skor POGO. Keberhasilan intubasi endotrakea adalah intubasi endotrakea yang dilakukan kurang dari 1 menit dan pipa endotrakea berada pada trakea. Lama waktu intubasi endotrakea didefinisikan sebagai waktu yang dibutuhkan sejak insersi bilah laringoskop di antara gigi seri hingga balon pipa endotrakea dikembangkan.

Analisis data meliputi analisis deskriptif dan uji hipotesis. Data disajikan dalam bentuk persentase (\%) untuk variabel kategorik dan rerata \pm standar deviasi (SD), median, range (min.-maks.) untuk variabel numerik. Uji statistik dilakukan dengan uji-t tidak berpasangan apabila data berdistribusi normal dan alternatif Uji Wilcoxon bila data tidak berdistribusi normal. Analisis statistik untuk data kategorik berpasangan diuji dengan uji McNemar dan Marginal homogenity. Data diolah dengan program statistical product and service solution (SPSS) versi 24.0 for windows. 

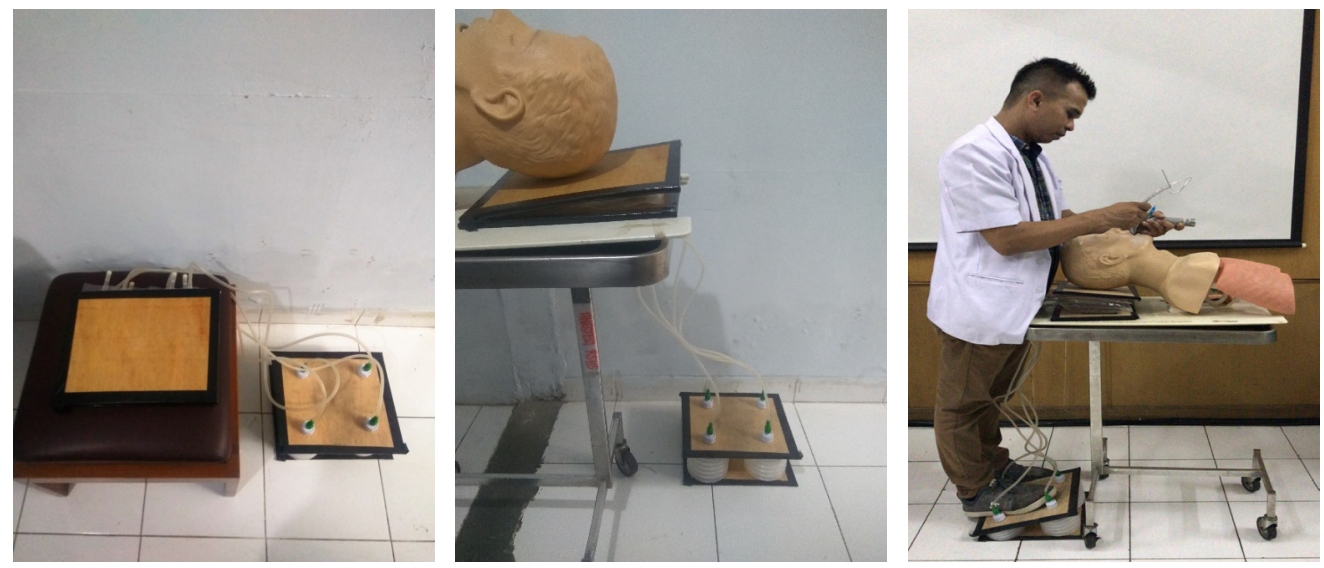

Gambar Bantal Intubasi Modifikasi

Dikutip dari: Dokumentasi pribadi

\section{Hasil}

Hasil penelitian menunjukkan dari 31 subjek penelitian dengan level kompetensi 3 (mandiri) dengan rentang usia 29-40 tahun (Tabel 1).

Pada penelitian ini didapatkan nilai keberhasilan intubasi endotrakeal yang sama pada kelompok bantal standar (A) dan kelompok bantal modifikasi (B) dengan perbedaan yang tidak bermakna $(p>0,05$; Tabel 2).

Hasil penelitian menunjukkan bahwa waktu intubasi pada kelompok bantal standar lebih singkat dibanding dengan kelompok bantal modifikasi dengan perbedaan yang bermakna ( $\mathrm{p}<0,05$; Tabel 3).

Hasil penelitian menunjukkan bahwa skor POGO pada kelompok B lebih baik dibanding dengan A dengan perbedaan yang bermakna

\section{Tabel 1 Karakteristik Subjek Penelitian}

\begin{tabular}{lc}
\hline \multicolumn{1}{c}{ Variabel } & $\mathbf{n = 3 1}$ \\
\hline Usia (tahun) & $33,95 \pm 0,47$ \\
Mean \pm SD & 33 \\
Median & $29-40$ \\
Range (min.-maks.) & 31 \\
Level kompetensi 3 (mandiri) & \\
\hline
\end{tabular}

Keterangan: karakteristik subjek berdasar atas level kompetensinya. Usia subjek penelitian memiliki rerata sebesar $33,95 \pm 0,47$

Tabel 2 Perbandingan Keberhasilan Intubasi Menggunaan Bantal Modifikasi dengan Bantal Standar

\begin{tabular}{|c|c|c|c|}
\hline \multirow[b]{2}{*}{ Keberhasilan Intubasi } & \multicolumn{2}{|c|}{ Kelompok } & \multirow[b]{2}{*}{ Nilai p } \\
\hline & $\begin{array}{c}\text { Bantal Modifikasi } \\
(n=31)\end{array}$ & $\begin{array}{c}\text { Bantal Standar } \\
(n=31)\end{array}$ & \\
\hline Berhasil & 31 & 31 & 1,000 \\
\hline Tidak berhasil & 0 & 0 & \\
\hline
\end{tabular}

Keterangan: untuk data kategorik nilai p dihitung berdasar atas Uji Mcnemar. Nilai kemaknaan berdasar atas nilai $p<0,05$. Tanda* menunjukkan nilai $p<0,05$ artinya signifkan atau bermakna secara statistik 
Tabel 3 Perbandingan Lama Intubasi Endotrakeal Menggunakan Bantal Standar dengan Bantal Modifikasi

\begin{tabular}{lccc}
\hline \multirow{2}{*}{ Waktu Intubasi } & \multicolumn{2}{c}{ Kelompok } & \multirow{2}{*}{ Nilai p } \\
\cline { 2 - 3 } & $\begin{array}{c}\text { Bantal Modifikasi } \\
(\mathbf{n = 3 1 )}\end{array}$ & $\begin{array}{c}\text { Bantal Standar } \\
(\mathbf{n = 3 1})\end{array}$ & \\
\hline Mean \pm SD & $8,72 \pm 3,309$ & $9,61 \pm 2,856$ & 0,0005 \\
Median & 8,42 & 8,72 & \\
Range (min.-maks.) & $3,00-16,52$ & $5,92-16,15$ & \\
\hline
\end{tabular}

Keterangan: data numerik nilai p diuji dengan uji T berpasangan apabila data berdsitribusi normal dengan alternatif uji Wilcoxon, apabila data tidak berdistribusi normal. Nilai kemaknaan berdasar atas nilai $\mathrm{p}<0,05$. Tanda* menunjukkan nilai $\mathrm{p}<0,05$ artinya signifkan atau bermakna secara statistik

Tabel 4 Perbandingan Skor POGO (\%) antara Bantal Modifikasi dan Bantal Standar

\begin{tabular}{lccc}
\hline \multirow{2}{*}{ Skor POGO (\%) } & \multicolumn{2}{c}{ Kelompok } & \multirow{2}{*}{ Nilai p } \\
\cline { 2 - 3 } & $\begin{array}{c}\text { Bantal Modifikasi } \\
(\mathbf{n = 3 1})\end{array}$ & $\begin{array}{c}\text { Bantal Standar } \\
(\mathbf{n = 3 1 )}\end{array}$ & $0,000^{* *}$ \\
\hline Mean \pm SD & $90,16 \pm 6,890$ & $73,35 \pm 6,421$ & \\
Median & 90 & 80 & \\
Range (min.-maks.) & $80-100$ & $70-90$ & \\
\hline
\end{tabular}

Keterangan: data numerik nilai p diuji dengan uji t berpasangan apabila data berdsitribusi normal dengan alternatif Uji Wilcoxon apabila data tidak berdistribusi normal. Nilai kemaknaan berdasar atas nilai $\mathrm{p}<0,05$.Tanda* menunjukkan nilai $\mathrm{p}<0,05$ artinya signifkan atau bermakna secara statistik

$(\mathrm{p}<0,05 ;$ Tabel 4).

\section{Pembahasan}

Data karakteristik subjek penelitian dengan level kompetensi 3 menunjukkan kemampuan yang sama dalam melakukan tindakan intubasi endotrakeal, termasuk melakukan tindakan intubasi sulit. Data ini berpengaruh pada tingkat keberhasilan dan waktu yang diperlukan dalam melakukan tindakan (Tabel 1).

Hasil penelitian menunjukkan nilai sama untuk keberhasilan antara intubasi menggunakan bantal standar dan bantal modifikasi (Tabel 2). Posisi kepala dan leher yang tepat merupakan salah satu faktor penting dalam melakukan tindakan direct laryngoscopy dan intubasi endotrakeal agar meminimalkan tingkat cedera trakea, lama tindakan, pengulangan tindakan, dan mengurangi trauma. Sniffing position dianjurkan sebagai posisi standar tindakan direct laryngoscopy langsung karena aksis orofaringolaring mendekati satu garis lurus. Tingkat keberhasilan menggunakan bantal intubasi lebih mudah dilakukan karena ketinggian bantal menghasilkan posisi intubasi yang lebih baik dan lebih mudah karena aksis lebih lurus. Penelitian lain menyatakan penggunaan bantal intubasi yang dapat dipompa dan diatur ketinggiannya menghasilkan posisi untuk intubasi yang lebih baik karena tercapainya aksis yang lurus dari mulut, faring, dan laring sehingga lebih mudah dalam melakukan tindakan intubasi dan tingkat keberhasilan lebih tinggi dibanding dengan bantal intubasi standar. Hasil penelitian ini persentase keberhasilan intubasi endotrakea menggunakan bantal intubasi modifikasi dan bantal intubasi standar sama, yaitu $100 \%$. Baik bantal intubasi standar atau bantal intubasi modifikasi menghasilkan sniffing position sehingga memberikan tampilan direct laryngoscopy yang lebih baik dengan memperbesar sudut oksipito-atlanto-aksial 
dan memperbesar ruang submandibular sehingga membuat laring, faring, dan akses mulut dalam satu garis lurus, namun tindakan intubasi menggunakan bantal intubasi modifikasi diharapkan dapat meningkatkan kemudahan karena bersifat lebih dinamis dibanding dengan bantal standar dalam menciptakan posisi intubasi yang paling ideal. ${ }^{5,6}$

Hasil penelitian menunjukkan waktu intubasi (Tabel 3) menggunakan bantal standar (A) 9,61 $\pm 2,856$ detik, sedangkan bantal modifikasi 8,72 $\pm 3,309$ detik. Hasil ini menunjukkan bahwa lama waktu yang dibutuhkan untuk intubasi endotrakeal menggunakan bantal modifikasi lebih cepat dibanding dengan bantal modifikasi. Intubasi adalah tindakan yang dinamis, tiap individu yang melakukan tindakan intubasi tidak akan menghasilkan hasil yang sama oleh karena itu bantal intubasi modifikasi akan lebih fleksibel dan dinamis untuk menghasilkan posisi intubasi yang lebih baik karena tercapainya aksis yang lurus dari mulut, faring, dan laring sehingga lebih mudah dalam melakukan tindakan intubasi dan tingkat keberhasilan lebih tinggi dibanding dengan bantal intubasi standar. Memang dalam praktiknya perbedaan 1-3 detik tidak terlalu signifikan karena tujuan akhir yang diharapkan adalah keselamatan pasien itu sendiri, tetapi dengan didapat hasil seperti ini menunjukkan bahwa bantal intubasi modifikasi lebih membantu memberikan visualisasi yang lebih baik. Penelitian ini sesuai dengan penelitian penggunaan bantal intubasi modifikasi dengan pompa memberikan waktu yang lebih baik dibanding dengan bantal intubasi standar.

Hasil penelitian menunjukkan bahwa skor POGO pada kelompok bantal modifikasi (B) $90,16 \pm 6,890$ lebih baik dibanding dengan kelompok bantal standar (A) 73,35 $\pm 6,421$ dengan perbedaan yang bermakna (Tabel 4). Sesuai beberapa penelitian terakhir mengenai bantal intubasi yang dilakukan baik kepada pasien ataupun kadaver, tindakan elevasi kepala akan memperbaiki visualisasi glotis, dengan cara membuat sudut ekstensi oksipitoatlanto-aksial lebih besar. Selain itu, sniffing position memperbesar ruang submandibula dan membuat keselarasan aksis vertikal mandibula, basis lidah dan laring sehingga memperbaiki visualisasi glotis., dan juga tindakan elevasi kepala akan menyebabkan laring akan berada lebih ke posterior sehingga mengakibatkan glotis akan lebih terlihat saat dilakukan intubasi. ${ }^{6-10}$

\section{Simpulan}

Waktu intubasi endotrakea pada manekin menggunakan bantal modifikasi lebih singkat dibanding dengan bantal standar dengan tingkat keberhasilan yang sama pada kedua perlakuan. Penelitian lebih lanjut menggunakan bantal intubasi modifikasi pada tata laksana jalan napas sulit dan uji keamanan pada manusia mengingat kegunaannya pada hasil penelitian manekin.

\section{Daftar Pustaka}

1. Hagberg CA, Artime CA. Airway management in adult. Dalam: Miller RD, penyunting. Edisi ke-8. Philadelphia: Elsevier Saunders; 2015. hlm. 1647-83.

2. El-Orbany M, Woehlck H, Salem MR. Head and neck postion for direct laryngoscopy. Anesth Analg. 2011;113(1):103-9.

3. Horton WA, Fahy L, Charters P. Defining a standard intubating position using "angel finder". Br J Anaesth. 1989;62(1):6-12.

4. Adnet F, Baillard C, Borron SW, Denantes C, Lefebvre L. Randomized study comparing the "sniff position: with simple head extension for laryngoscopic view in elective surgery patients. Anesthesiology. 2001;95(4):836-41.

5. Kitamura Y, Isono S, Suzuki N, Sato $\mathrm{Y}$, Nishino T. Dynamic interaction of craniofacial structure during head positioning and direct laryngoscopy in anesthezied patients with and without difficult laryngoscopy. Anesthesiology. 2007;107(6):875-83.

6. Park SH, Park HP, Jeon YT, Hwang JW, Kim JH, Bahk JH. A comparison of direct laryngoscopic views depending on pillow 
height. J Anesth 2010;24(4):526-30.

7. Kim H, Chang JE, Min SW, Lee JW, Ji S, Hwang JY. A comparison of direct laryngoscopy views in different head and neck position in edentulous patient. Am J Emerg Med. 2016;34(9);1855-8.

8. Schmitt JH, Mang H. Head and neck elevation beyond the sniffing position improves laryngeal view in case of difficult direct laryngoscopy. J Clin Anesth. 2002;14(5):335-8.

9. Levitan RM, Mechem CC, Ochroch EA. Headelevated laryngoscopy position: improving laryngeal exposure during laryngoscopy by increasing head elevation. Ann Emerg Med. 2003;41(3):322-30.

10. Rich JM. Use of an elevation pillow to produce the head-elevated laryngoscopy position for airway management in morbidly obese and large framed patients. Anesth Analg. 2004;98(1):264-5.

11. Mathis A, Muller JP. Intubation time with and without inflatable intubation device. Eur J Anaesthesiol. 2007;24(1):197-8.

12. Cook TM, Scott S, Mihai R. Litigation related to airway and respiratory complications of anaesthesia: an analysis of claims against the NHS in England. 1995-2007. Anaesthesia. 2010;65(6):556-63.
13. Cooper JB, Taqueti VR. A brief history of the development of mannequin simulators for clinical education and training. Qual Saf Health Care. 2004;13(Suppl 1):i11-8.

14. Schaefer JJ 3rd. Simulators and difficult airway management skills. Paediatr Anaesth. 2004;14(1):28-37.

15. Rai MR, Popat MT. Evaluation of airway equipment: Man or manikin?. Anaesthesia. 2011;66(1):1-39.

16. Cook TM. Novel airway devices: Spoilt for choice?. Anaesthesia. 2003;58(2):107-10.

17. Siu LW, Boet S, Borges BC, Bruppacher HR, LeBlanc V, Naik VN, dkk. Highfidelity simulation demonstrates the influence of anesthesiologists' age and years from residency on emergency cricothyroidotomy skills. Anesth Analg. 2010;111(4):955-60.

18. Kory PD, Eisen LA, Adachi M, Ribaudo VA, Rosenthal ME, Mayo PH. Initial airway management skills of senior residents: Simulation training compared with traditional training. Chest. 2007;132(6):1927-31.

19. Jones F, Passos-Neto CE, Braghioli OFM. Simulation in medical education: brief history and methodology. Prin Pract Clin Res. 2015;1(2):56-63. 